\title{
CCL18 overexpression predicts a worse prognosis in oral squamous cell carcinoma (OSCC)
}

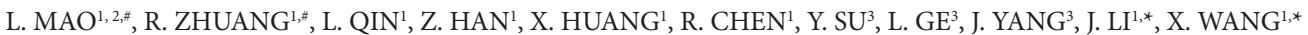 \\ ${ }^{1}$ Department of Oral and Maxillofacial Surgery, Capital Medical University School of Stomatology, Capital Medical University, Beijing, China; \\ ${ }^{2}$ Department of Stomatology, Beijing Jishuitan Hospital, Beijing, China; ${ }^{3}$ Beijing Institute of Dental Research, Capital Medical University School \\ of Stomatology, Capital Medical University, Beijing, China
}

*Correspondence: wangxj@ccmu.edu.cn, lijun3021@aliyun.com

${ }^{*}$ Contributed equally to this work.

Received May 21, 2018 / Accepted July 22, 2019

\begin{abstract}
Oral squamous cell carcinoma (OSCC) presents severe morbidity and high mortality owing to local recurrence or remote metastasis. Molecular markers, including chemokines, might provide more efficient prognostic information or even therapeutic targets for the treatment of OSCC. Using quantitative RT-qPCR, we found that CCL18 was dramatically overexpressed in 30 OSCC tissues at the mRNA level in comparison with their adjacent non-cancerous oral mucosa tissues and 15 oral mucosa tissues from non-malignant patients. We then analyzed the relationship between CCL18 overexpression and patient clinical characters and outcomes using immunohistochemistry staining (IHC) in 102 paired OSCC cancerous and adjacent non-cancerous tissues; the increase in CCL18 expression was significantly higher in male patients $(p=0.047)$, tumors of the palate and floor of the mouth $(\mathrm{p}=0.014)$, patients with positive lymph node metastasis $(\mathrm{p}=0.007)$, and patients with poor tumor differentiation $(\mathrm{p}=0.029)$. The median overall survival time and time-to-recurrence were 80.6 and 61.4 months in patients with high CCL18 expression, respectively, as against 93.4 and 81.6 months in patients with comparatively lower CCL18 expression, respectively ( $\mathrm{p}=0.033$ and 0.012 , respectively; log-rank test). Multivariate analyses indicated age, poor differentiation, and CCL18 levels to be independent prognostic factors for predicting both overall and diseasefree survival time. Our study suggests that CCL18 is a novel candidate marker for the OSCC malignancy and prognosis, including lymph node metastasis, time-to-recurrence, and disease-free survival time.
\end{abstract}

Key words: oral squamous cell carcinoma, biomarker, CCL18, survival, prognosis

Oral squamous cell carcinoma (OSCC) is the most common oral malignant tumor; it originates from the oral epithelium and develops into carcinoma in situ. According to statistics, more than $90 \%$ of oral malignant tumors are oral squamous cell carcinomas (OSCC) [1]. Globally, OSCC accounts for $2-4 \%$ of all cancers, and due to the lack of efficient early diagnosis and treatment methods, the 5-year survival rate is still only about $50 \%$. In Asia, due to the betel nut chewing habits, OSCC has become one of the six most common malignant tumors, among lung, liver, stomach, colorectal, and prostate cancers [2]. Invasion and early metastasis of OSCC result in low 5-year survival rates, in spite of the advancement in surgery and chemo- and radiotherapy in the past decades. Hence, investigation and understanding of biomarkers in OSCC might contribute to further improvement in its diagnosis and treatment. However, the key molecular markers are yet to be identified.
The cancer immune microenvironment plays a key role in tumorigenesis and invasion [3,4]. In addition to several types of immune cells, the cancer immune microenvironment involves a variety of chemokines. Chemokine ligand 18 (CCL18) belongs to the small cytokine family, and these are involved in immunoregulatory processes [5]. In tumor tissues, there seems to be a positive feedback loop in order to increase the CCL18 expression. A small amount of CCL18 can promote the differentiation and maturation of immature dendritic cells and the differentiation of the macrophage M2 subtype, which can further produce a large amount of CCL18. CCL18 ultimately plays an immunosuppressive role by promoting the differentiation of Treg cells and not $\mathrm{T}$ cells $[4,6]$. Additionally, recent studies have also shown that CCL18 can contribute to the proliferation and invasion of OSCC through the AKT signaling pathway [7] and the mammalian target of rapamycin pathway (mTOR) [8]. 
Although CCL18 has promoted OSCC cell line proliferation and invasion in vitro, clinically there is still no prospective evidence to support the clear correlation between CCL18 and OSCC malignancy. In our study, after verification of CCL18 expression changes between normal oral mucosae and OSCC tissues using RT-PCR, we prospectively harvested samples of OSCC tissues and their corresponding neighboring non-cancerous tissues in 102 patients. Patients were constitutively followed up and all the tissues were immunostained to detect the level of CCL18. We found that CCL18 expression is strongly related to OSCC survival rate, lymph node metastasis, and tumor differentiation.

\section{Patients and methods}

Patients and samples. This study included a total of 147 patients (30 OSCC patients and 15 non-cancer patients for RT-qPCR study of the expression of CCL18; and 102 patients for paired IHC study of CCL18 expression). All patients underwent primary OSCC surgical resection or other non-cancer surgeries between May 2009 and May 2013 at Beijing Stomatological Hospital. The 132 OSCC patients had no previous radiotherapy and/or chemotherapy or other malignant diseases. Clinicopathological information including gender, age, tumor location, tumor grade, tumor (T) classification, node $(\mathrm{N})$ classification, and tumor, node, and metastases (TNM) stage was obtained from clinical and pathological records. The TNM stages of patients were classified according to the 2012 American Joint Committee on Cancer Staging System. According to the guidelines of our hospital, surgical salvage is the first choice if the tumor is operable. Otherwise, patients will undergo salvage chemotherapy or chemoradiation therapy, which were excluded from this study. To detect CCL18 expression, fresh tissues were obtained from patients during the operation. A total of 102 OSCC cases with paired cancerous and non-cancerous peritumoral tissues were used as a prognosis study cohort whose tissues were immunohistochemically studied. A total of 15 patients with normal mucosae and an additional 30 OSCC cases with paired cancerous tissues and non-cancerous peritumoral tissues were used for quantitative RT-qPCR assays. These tissues were subjected to histological confirmation using frozen sections before quantitative RT-PCR assays and immunohistochemical studies.

Patient follow-ups were carried out by two physicians unaware of the study until June 2017. Complete followup data were available for all 102 cases, which served as a prognosis study cohort.

All participants in this study have signed written informed consent, and this investigation was performed in accordance with the Declaration of Helsinki and has been approved by the Ethics of Committee of Beijing Stomatological Hospital, Capital Medical University.

RNA extraction and quantitative RT-PCR (RT-qPCR). Tissue samples were dip frozen in liquid nitrogen and immedi- ately used for RNA extraction. The tissue was homogenized using the MX-F Vortex mixer (SCILOGEX, LLC, USA). Total RNA was prepared from the frozen tissue samples using Trizol reagent (Invitrogen) according to the manufacturer's instructions. The RNA (500 ng) was then reverse-transcribed into cDNA using HiScript II Reverse Transcriptase (Vazyme, Nanjing, China). For RT-qPCR, the primers for CCL18 were as follows: CCL18 forward: CTGCCCAGCATCATGAAGG; CCL18 reverse: CCTCAGGCATTCAGCTTCAG. The primers for actin were as follows: actin forward: TGACGTGGACATCCGCAAAG; actin reverse: CTGGAAGGTGGACAGCGAGG

Data were represented as mean \pm s.d. Actin was used as an internal control for comparison and normalization of the data. Assays were performed in triplicate using the Roche LightCycler 96 System.

Immunohistochemistry. Tissues were fixed in 10\% neutral buffered formalin overnight, then embedded in paraffin after a series of dehydration steps using gradient series of alcohol and transferred to xylene. Blocks of formalin-fixed, paraffin-embedded tissues were cut into 4 $\mu \mathrm{m}$ sections, deparaffinized with xylene, and rehydrated in a series of ethanol washes $(100,90,80$, and $70 \%)$. Slides were washed with phosphate-buffered saline (PBS) and treated with $3 \% \mathrm{H}_{2} \mathrm{O}_{2}$ for 30 min to block endogenous peroxidase activity. Subsequently, sections were put into a water bath in $10 \mathrm{mM}$ citrate buffer $(\mathrm{pH} 6.0)$ at $90^{\circ} \mathrm{C}$ to unmask epitopes. After antigen retrieval, sections were incubated with diluted anti-CCL18 primary antibody (NBP1-79940; Polyclonal; 1:300; NOVUS Biologicals, Littleton, CO, USA) or CD206 primary antibody (ab64693; Polyclonal; 1:2000; Abcam, Cambridge, UK) for $2 \mathrm{~h}$ followed by washing with PBS. Thereafter, corresponding biotin conjugated secondary antibodies were applied for $0.5 \mathrm{~h}$. Horseradish peroxidase/ streptavidin conjugate (PicTure-Plus kit; Zymed, South San Francisco, CA, USA) was then applied to the sections for 30 min followed by washing with PBS. Finally, the sections were incubated in diaminobenzidine (CCL18 staining, for $5 \mathrm{~min}$ ) or 3-amino-9-ethylcarbozole (CD206 staining, for $10 \mathrm{~min}$ ) to develop signals. A negative control, without the primary antibody, was run simultaneously. Positive immunostaining was defined as cytoplasmic and/or membrane immunoreactivity.

For CCL18, serial sections were examined under a light microscope (BH-2; Olympus, Japan) with a digital camera (DP72; Olympus). Images of low-power magnification $(\times 200)$ fields were captured from each slide at random. Staining intensity was evaluated by mean optical density (MOD). The MODs of each image were counted and measured using Image-Pro Plus v6.0 software (Media Cybernetics Inc, Bethesda, MD, USA). All images were taken using the same microscope and camera set. For CD206 staining, the sections were examined under a light microscope (BH-2; Olympus, Japan) with a digital camera (DP72; Olympus). Images of interesting fields were captured from the slides. 
Statistical analysis. The SPSS20.0 system was used for statistical analysis. For RT-PCR analysis, the differences in the CCL18 expression between 30 OSCC tissues, their corresponding peritumoral non-cancerous tissues, and 15 normal mucosa tissues were evaluated using the Wilcoxon-MattWhitney test. For immunohistochemistry analysis, CCL18 expression in 102 paired OSCC tissues and corresponding peritumoral non-cancerous tissues was half-quantified using MOD values $\left(\mathrm{MOD}_{\mathrm{ca}}\right.$ and $\left.\mathrm{MOD}_{\text {para }}\right)$. The expression changes in CCL18 were represented as $\mathrm{MOD}_{\text {incre }}\left(\mathrm{MOD}_{\mathrm{ca}} /\right.$ $\left.M O D_{\text {para }}\right)$. Associations between the expression changes of CCL18 $\left(\mathrm{MOD}_{\text {incre }}\right)$ and clinicopathological characteristics were evaluated using the chi-square test. The expression levels of CCL18 in all OSCC cases were separated into two groups as $\mathrm{MOD}_{\mathrm{IL}}$ (comparatively low expression level) and $\mathrm{MOD}_{\mathrm{IH}}$ (comparatively high expression level) according to the median $\mathrm{MOD}_{\text {incre }}$ value.

Overall survival (OS), disease-free survival (DFS), and TTR (time-to-recurrence) of patients were compared between the $M O D_{I L}$ and $M O D_{I H}$ groups according to the Kaplan-Meier method. Other potential clinical and histopathologic variables were also tested for prognostic significance evaluated using 3-year and 5-year OS and DFS rates. Overall survival was measured from the date of surgery to

Table 1. Patient and tumor characteristics $(n=102)$.

\begin{tabular}{|c|c|c|c|}
\hline Variable & & No. of patients & $\%$ \\
\hline \multirow{2}{*}{ Age, y } & $<60$ & 51 & 50.0 \\
\hline & $\geq 60$ & 51 & 50.0 \\
\hline \multirow{2}{*}{ Gender } & Female & 48 & 47.1 \\
\hline & Male & 54 & 52.9 \\
\hline \multirow{5}{*}{ Tumor location } & Tongue & 53 & 51.9 \\
\hline & Palate & 7 & 6.9 \\
\hline & Buccal & 9 & 8.8 \\
\hline & Floor of mouth & 13 & 12.7 \\
\hline & Gingival & 20 & 19.6 \\
\hline \multirow{4}{*}{$\begin{array}{l}\text { Pathologic } \\
\text { T classification }\end{array}$} & pT1 & 37 & 36.2 \\
\hline & pT2 & 51 & 50.0 \\
\hline & pT3 & 8 & 7.8 \\
\hline & pT4 & 6 & 5.9 \\
\hline \multirow{3}{*}{$\begin{array}{l}\text { Pathologic } \\
\text { lymph node } \\
\text { metastasis }\end{array}$} & Negative (pN0) & 65 & 63.7 \\
\hline & Positive (pN1-pN3) & 37 & 36.3 \\
\hline & I & 28 & 27.5 \\
\hline \multirow{3}{*}{$\begin{array}{l}\text { TNM tumor } \\
\text { stage }\end{array}$} & II & 30 & 29.4 \\
\hline & III & 32 & 31.4 \\
\hline & IV & 12 & 11.8 \\
\hline \multirow{3}{*}{$\begin{array}{l}\text { Tumor differen- } \\
\text { tiation }\end{array}$} & Well & 72 & 70.6 \\
\hline & Moderate & 20 & 19.6 \\
\hline & Poor & 10 & 9.8 \\
\hline \multirow{3}{*}{$\begin{array}{l}\text { Vital status at } \\
\text { follow-up }\end{array}$} & Alive & 73 & 71.6 \\
\hline & Death from OSCC & 26 & 25.5 \\
\hline & Death from other than OSCC & 3 & 2.9 \\
\hline
\end{tabular}

Abbreviation: OSCC, oral squamous cell carcinoma. the date of the last follow-up examination or death, whereas DFS was measured from the date of surgery to the date on which recurrence and/or subsequent lymph node metastasis was first detected. Overall survival was defined as the interval between surgery and death or the last observation taken. The DFS was defined as the time between surgery and the date of any adverse event, whichever appeared first. Time-to-recurrence was defined as from the date of tumor resection to the detection of tumor recurrence. For the analysis of prognostic factors, differences in survival rates were evaluated using the log-rank test. Univariate and multivariate analyses of OS and DFS were performed using the Cox proportional hazards regression model. All statistics were 2-sided, and results were considered statistically significant at a probability of $\mathrm{p}<0.05$.

\section{Results}

Clinicopathological characteristics and outcomes. The clinicopathologic characteristics of 102 OSCC patients whose specimens were used for IHC analysis are listed in Table 1 . There were 54 males and 48 females, with a median age of 60 years (range, 33-83 years). The rate of pathological regional lymph node metastasis at the time of surgery was $36.3 \%$. Among all 102 OSCC tissues, 72,20 , and 10 cases were well, moderately, and poorly differentiated, respectively (according to Broder's classification). At the time of the last follow up, 73 cases of the 102 patients $(71.6 \%)$ were alive, 26 cases $(25.5 \%)$ had died of OSCC, and 3 cases $(2.9 \%)$ had died of other causes. Overall, 41 patients developed recurrent diseases, including 16 local recurrences (39.0\%), 21 subsequent regional lymph node metastases (51.2\%), and 6 distant recurrences (14.6\%). The mean observation time was 61 months (range, 5-104 months).

Increase in CCL18 expression in OSCC. First, CCL18 expression was analyzed by RT-qPCR in 30 paired OSCC tissues and their adjacent non-cancerous oral epithelium tissues and another 15 normal oral mucosa specimens, which were harvested from non-tumor patients. The RT-qPCR analysis results are shown in Figure 1. Here, CCL18 was abundantly expressed in cancerous tissues $1.8612(0.3179$, 4.4351 ), in comparison. CCL18 expression in adjacent non-cancerous tissues was $0.2305(0.0788,0.8788)$, and in normal oral tissues $0.3200(0.2300,0.6500)$. There were statically significant differences between these groups (normalparatumor $\mathrm{p}=0.485$, normal-tumor $\mathrm{p}=0.012$, tumorparatumor $\mathrm{p}=0.001$ ).

Secondly, the paired IHC staining of tissues from 102 OSCC cases showed that CCL18 expression increased in all the OSCC tissues when compared to their corresponding non-cancerous tissues. CCL18 was mainly expressed in OSCC cells, and also expressed by some cells in the mesenchymal tissue surrounding OSCC (Figure 1, ×200 magnification). CD206 was mainly expressed in mesenchymal tissue (Figure S1). 


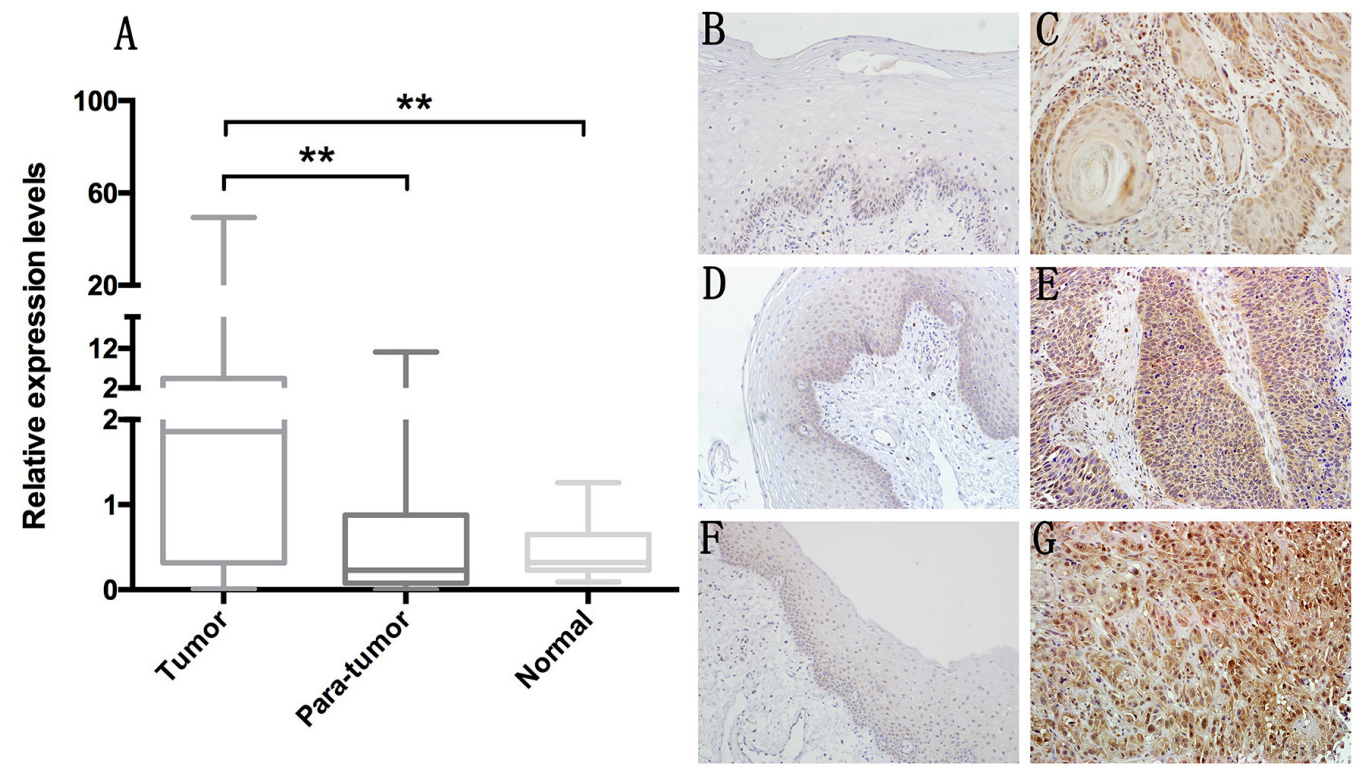

Figure 1. CCL18 expression in OSCC tumor, para-tumor, and normal oral mucosae. A) The mRNA expression levels of CCL18 were evaluated by qRT-PCR in 30-paired tumor and para-tumor tissues of OSCC patients and in 10 normal oral mucosa specimens, which were harvested from nonmalignant patients. Results were normalized against the expression level of $\beta$-actin mRNA in each sample and then analyzed by Mann-Whitney U-test, ${ }^{* *} \mathrm{p}<0.05$, box plots display the median, 25 th and 75 th percentiles. It showed that CCL18 was abundantly expressed in the cancerous tissues 1.8612 $(0.3179,4.4351)$, in comparison, CCL18 expression in adjacent non-cancerous tissues was $0.2305(0.0788,0.8788)$, and in the normal oral tissues $0.3200(0.2300,0.6500)$. There were statically significant differences between these groups (normal-paratumor $\mathrm{p}=0.485$, normal-tumor $\mathrm{p}=0.012$, tumor-paratumor $\mathrm{p}=\mathbf{0 . 0 0 1}$ ). B, D, F) Stratified squamous epithelium of the peritumoral non-cancerous tissues. C, E, G) The corresponding OSCC tissues presented as the well, moderately and poorly differentiated subtypes. It showed that CCL18 expression in OSCC tissues obviously increased compared to their corresponding para-tumor tissues; and the expression levels were also augmented as the differentiation grade worsened. The magnification of the figures was $200 \times$.

Association between increased CCL18 expression and clinicopathological characteristics. As in PCR assays, we found in IHC analysis that CCL18 expression was also substantially increased in OSCC tissues. We used $\mathrm{MOD}_{\text {inc }}$ $\left(\mathrm{MOD}_{\mathrm{ca}} / \mathrm{MOD}_{\text {para }}\right)$ to represent the changes of expression. By a median value, $M O D_{\text {inc }}$ values of each case were separated into two groups as $\mathrm{MOD}_{\mathrm{IH}}$ (comparatively high) and $\mathrm{MOD}_{\mathrm{IL}}$ (comparatively low), representing the highly increased group and the moderately increased group respectively. Associations between increased expression of CCL18 and clinicopathological characteristics are summarized in Table 2. Shortly, greater increase in CCL18 expression was found in males ( $\mathrm{p}=0.047)$, patients with tumors on the palate and floor of the mouth $(\mathrm{p}=0.014)$, and patients with positive lymph node metastasis $(\mathrm{p}=0.007)$ and poor tumor differentiation $(\mathrm{p}=0.029)$.

Association between increased CCL18 expression and OS, TTR, and DFS. The OS, TTR, and DFS curves were depicted by the Kaplan-Meier analysis using SPSS 20.0 software. Results showed that the mean OS time for $\mathrm{MOD}_{\mathrm{IH}}$ patients was 80.6 months when compared with 93.4 months for $\mathrm{MOD}_{\text {IL }}$ patients $(\mathrm{p}=0.033$, log-rank test; Figure $2 \mathrm{~A})$. The mean TTR for $\mathrm{MOD}_{\mathrm{IH}}$ patients was 61.4 months, while that for $\mathrm{MOD}_{\text {IL }}$ patients was 81.6 months ( $\mathrm{p}=0.012$, log-rank test; Figure $2 \mathrm{~B}$ ). The mean DFS time for $\mathrm{MOD}_{\mathrm{IH}}$ patients was
73.5 months, while that for $\mathrm{MOD}_{\text {IL }}$ patients was 91.4 months ( $\mathrm{p}=0.024, \log$-rank test; Figure 2C).

Analysis of prognostic factors on OS. The 3-year and 5 -year OS rates of the entire patient population were $82.1 \%$ and $76.8 \%$, respectively. Univariate analysis of the OS rate among each variable as determined by the log-rank test is listed in Table 3 . The cumulative overall survival rate of patients with comparatively increased CCL18 was significantly worse than for patients with other covariates $(\mathrm{p}=0.033)$. The following variables were also found to be associated with poor prognosis: age $(\mathrm{p}=0.005)$, poor differentiation ( $\mathrm{p}=0.008)$. The univariate and multivariate analysis of OS using the Cox proportional hazards regression model is summarized in Table S1. Of the univariate analysis, age $(\mathrm{p}=0.009)$, poor differentiation $(\mathrm{p}=0.012)$, and high CCL18 expression ( $\mathrm{p}=0.040$ ) were found to be statistically significant prognostic factors affecting OS. Multivariate analysis of these 3 prognostic factors revealed that age $(\mathrm{p}=0.005)$, poor differentiation $(\mathrm{p}=0.035)$, high CCL18 expression $(\mathrm{p}=0.035)$ are independent prognostic factors for OS. Overall, these data indicate that high CCL18 expression is a statistically significant prognostic factor for OS in patients with OSCC.

Analysis of prognostic factors on DFS. The 3-year and 5 -year DFS rates of the entire patient population were $75.8 \%$ and $71.4 \%$, respectively. Univariate analysis of DFS among 
A

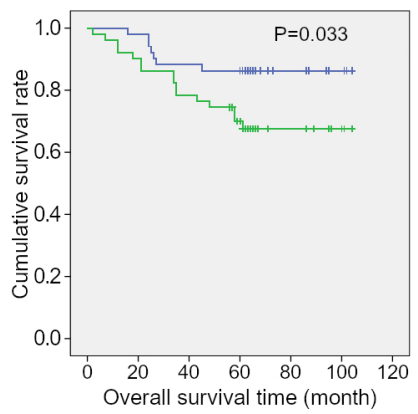

$\mathrm{B}$

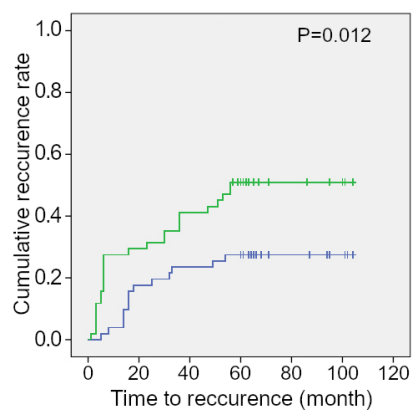

$\mathrm{C}$

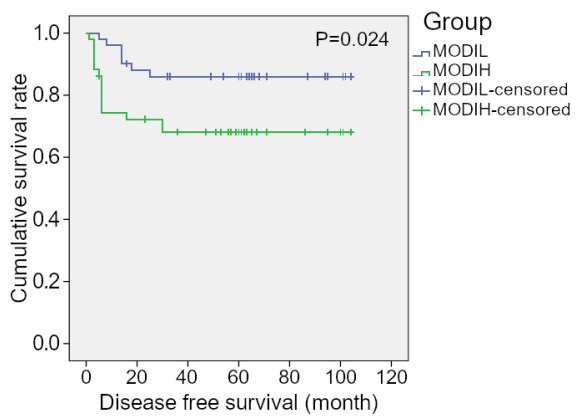

Figure 2. Association between increased CCL18 expression and OS, TTR, DFS. A) Correlation between increased CCL18 expression and the overall survival rate in patients with oral squamous cell carcinoma, as determined by the Kaplan-Meier method. The overall survival rate of patients who had comparatively high expression levels of CCL18 was statistically worse than that of patients with low expression. $\mathrm{MOD}_{\mathrm{IH}}(\mathrm{n}=51$, mean $=80.6 \mathrm{months})$, $\operatorname{MOD}_{\mathrm{IL}}(\mathrm{n}=51$, mean $=93.4$ months $), \mathrm{p}=\mathbf{0 . 0 3 3}$, log-rank test. B) Correlation between increased CCL18 expression and the time to recurrence rate in patients with oral squamous cell carcinoma, as determined by the Kaplan-Meier method. The recurrence rate of patients with comparatively high expression level of CCL18 was statistically high than that of patients with low expression, $\mathrm{MOD}_{\mathrm{IH}}(\mathrm{n}=51, \mathrm{mean}=61.4 \mathrm{months}), \mathrm{MOD} \mathrm{IL}_{\mathrm{I}}(\mathrm{n}=51, \mathrm{mean}=$ 81.6 months), $\mathrm{p}=\mathbf{0 . 0 1 2}$, log-rank test. C) Correlation between increased CCL18 expression and the disease-free survival rate in patients with oral squamous cell carcinoma, as determined by the Kaplan-Meier method. The disease-free survival rate of patients with comparatively high expression levels of CCL18 was statistically worse than that of patients with low expression. $\mathrm{MOD}_{\mathrm{IH}}(\mathrm{n}=51, \mathrm{mean}=73.5 \mathrm{months}), \mathrm{MOD}$ IL $(\mathrm{n}=51$, mean $=91.4 \mathrm{months})$, $\mathrm{p}=\mathbf{0 . 0 2 4}$, log-rank test.

Table 2. Association between CCL18 expression and clinicopathological factors.

\begin{tabular}{|c|c|c|c|c|}
\hline \multirow{2}{*}{ Variable } & & \multicolumn{2}{|c|}{ No. of patients (\%) } & \multirow[b]{2}{*}{ p-value } \\
\hline & & $\begin{array}{c}\text { Low } \\
(\mathrm{n}=51)\end{array}$ & $\begin{array}{c}\text { High } \\
(n=51)\end{array}$ & \\
\hline \multirow[t]{2}{*}{ Age, $y$} & $<60$ & 24 & 27 & \multirow{2}{*}{0.552} \\
\hline & $\geq 60$ & 27 & 24 & \\
\hline \multirow[t]{2}{*}{ Gender } & Female & 29 & 19 & \multirow{2}{*}{$0.047^{*}$} \\
\hline & Male & 22 & 32 & \\
\hline \multirow[t]{5}{*}{ Tumor location } & Tongue & 27 & 26 & \multirow{5}{*}{$0.014^{*}$} \\
\hline & Palate & 1 & 6 & \\
\hline & Buccal & 5 & 4 & \\
\hline & Floor of mouth & 3 & 10 & \\
\hline & Gingival & 15 & 5 & \\
\hline \multirow{4}{*}{$\begin{array}{l}\text { Pathologic } \\
\text { T classification }\end{array}$} & pT1 & 19 & 18 & \multirow{4}{*}{0.065} \\
\hline & pT2 & 26 & 25 & \\
\hline & pT3 & 1 & 7 & \\
\hline & pT4 & 5 & 1 & \\
\hline \multirow{2}{*}{$\begin{array}{l}\text { Pathologic lymph } \\
\text { node metastasis }\end{array}$} & Negative (pN0) & 39 & 26 & \multirow{2}{*}{$0.007^{*}$} \\
\hline & Positive (pN1-pN3) & 12 & 25 & \\
\hline \multirow{5}{*}{$\begin{array}{l}\text { TNM tumor } \\
\text { stage }\end{array}$} & I & 20 & 8 & \multirow{5}{*}{0.065} \\
\hline & II & 15 & 15 & \\
\hline & III & 11 & 21 & \\
\hline & IV & 5 & 7 & \\
\hline & Well & 39 & 33 & \\
\hline \multirow{2}{*}{$\begin{array}{l}\text { Tumor } \\
\text { differentiation }\end{array}$} & Moderate & 11 & 9 & \multirow[t]{2}{*}{$0.029 *$} \\
\hline & Poor & 1 & 9 & \\
\hline
\end{tabular}

"low" and "high" represented the two groups with different expression levels of CCL18 classified by the median MOD value. ${ }^{\star}$ p-value was statistically significant by the chi-square test.
Table 3. Relationship between overall survival rate and clinicopathological variables.

\begin{tabular}{|c|c|c|c|c|}
\hline \multirow{2}{*}{ Variable } & & 3-year OS & 5-year OS & \multirow{2}{*}{$\underset{\text { p-value }}{\text { CUM }}$} \\
\hline & & $\%$ & $\%$ & \\
\hline \multirow[t]{2}{*}{ Age, y } & $<60$ & 94.2 & 87.6 & $0.005^{*}$ \\
\hline & $\geq 60$ & 70 & 66 & \\
\hline \multirow[t]{2}{*}{ Gender } & Female & 81.2 & 79.2 & 0.739 \\
\hline & Male & 83.3 & 77.3 & \\
\hline \multirow{2}{*}{$\begin{array}{l}\text { Pathologic T } \\
\text { classification }\end{array}$} & $\mathrm{pT} 1+\mathrm{pT} 2$ & 86.4 & 79.3 & 0.154 \\
\hline & pT3+pT4 & 64.3 & 55.5 & \\
\hline \multirow{2}{*}{$\begin{array}{l}\text { Pathologic lymph } \\
\text { node metastasis }\end{array}$} & Negative (pN0) & 84.6 & 82.2 & 0.084 \\
\hline & Positive (pN1-pN3) & 81.1 & 66.1 & \\
\hline \multirow{2}{*}{$\begin{array}{l}\text { TNM tumor } \\
\text { stage }\end{array}$} & $\mathrm{I}+\mathrm{II}$ & 84.2 & 82.1 & 0.190 \\
\hline & $\mathrm{III}+\mathrm{IV}$ & 82.2 & 69.7 & \\
\hline \multirow{2}{*}{$\begin{array}{l}\text { Tumor } \\
\text { differentiation }\end{array}$} & Well + Moderate & 87.5 & 83.3 & $0.008^{*}$ \\
\hline & Poor & 73.3 & 59.8 & \\
\hline \multirow{2}{*}{$\begin{array}{l}\text { CCL18 } \\
\text { expression }\end{array}$} & Low & 88.2 & 85.7 & \multirow{2}{*}{$0.033^{*}$} \\
\hline & High & 78.4 & 67.5 & \\
\hline
\end{tabular}

Abbreviation: OS, overall survival. ${ }^{*}$ p-value was statistically significant by the log-rank test.

each variable as determined by the log-rank test is listed in Table 4 . The DFS rates of patients that were older $(\mathrm{p}=0.006)$, with poor tumor differentiation $(\mathrm{p}=0.003)$, and $\mathrm{MOD}{ }_{\mathrm{IH}}$ $(\mathrm{p}=0.024)$ were significantly worse than that of patients with other covariates. The univariate and multivariate analyses of DFS by the Cox proportional hazards regression model are summarized in Table S2. In the univariate analysis, age $(\mathrm{p}=0.001)$, poor differentiation $(\mathrm{p}=0.006)$, and high CCL18 expression ( $\mathrm{p}=0.032)$ were found to be statistically 
significant prognostic factors for DFS. Multivariate analysis of the 3 prognostic factors revealed that high CCL18 expression $(\mathrm{p}=0.0118)$, age $(\mathrm{p}=0.005)$, and poor differentiation $(\mathrm{p}=0.014)$ were independent prognostic factors for DFS.

\section{Discussion}

This study demonstrated that CCL18 was highly expressed in poorly differentiated OSCC and OSCC patients with early lymphatic metastasis and poor survival rate. This suggests that CCL18 is related to OSCC prognosis. To date, there is no prospective clinical study examining the relationship between CCL18 expression and OSCC development. Our study suggests for the first time that CCL18 expression could be used as one of the prognostic indicators of OSCC.

In vitro experiments have shown that increased CCL18 in OSCC cells could accelerate their migration and invasion. This could be blocked by treatment with a neutralizing anti-CCL18 antibody or CCL18 knockdown [7]. In addition, exogenous CCL18 induced OSCC cell epithelial-mesenchymal transition (EMT), during which E-cadherin (epithelial marker) decreased and $\mathrm{N}$-cadherin (mesenchymal marker) increased [8]. These studies support the results of our clinical study and suggest that CCL18 advances the epithelial cell proliferation and promotes EMT of OSCC, thereby promoting the growth and invasion of tumor tissue. In line with this, CCL18 is also related to the advancement of ovarian cancer [9] and non-small cell lung cancer [10] and deemed as a potential biomarker in ovarian cancer.

Besides its function directly in tumor cells, CCL18 is also one of the key mediators in the cancer immune microenvironment, according to some studies on cancers other than OSCC. Tumor-related CCL18 can activate macrophages and promote M2 differentiation $[5,11]$. The M2 macrophages secrete a variety of factors accelerating the proliferation of local cells, providing a favorable microenvironment for tumor cell proliferation [12]. At the same time, M2 macrophages also release a variety of immunosuppressive factors, promote Treg differentiation and inhibit $\mathrm{T}$ helper $T$ cell differentiation $[13,14]$. Thus, Treg and M2 macrophages provide a favorable immune microenvironment for the proliferation and invasion of tumor cells $[15,16]$. Nonetheless, there has been no study on CCL18's roles in the regulation of OSCC tumor immune microenvironment. Our study showed that CCL18 was expressed by OSCC cells and there were many CD206 (M2 macrophage marker) expressing macrophages surrounding the OSCC (Supplementary Figure 1), implying that CCL18 drives the advancement of OSCC through regulation of the immune microenvironment.

It has been demonstrated that CCL18 could promote cancer metastasis predominantly via binding to its receptor Nir1 (also named PITPNM3) in multiple human malignancies, including breast carcinoma [17, 18]. The PITPNM3CCL18 binding induces Pyk2 and Src mediated signaling,
Table 4. Disease-free survival rate in relation to clinicopathological variables.

\begin{tabular}{llccc}
\hline \multirow{2}{*}{ Variable } & & $\begin{array}{c}\text { 3-year } \\
\text { DFS }\end{array}$ & $\begin{array}{c}\text { 5-year } \\
\text { DFS }\end{array}$ & \multirow{2}{*}{$\begin{array}{c}\text { CUM } \\
\text { p-value }\end{array}$} \\
\cline { 3 - 4 } & & $\%$ & $\%$ & \\
\hline Age, y & $<60$ & 86.9 & 84.2 & \multirow{2}{*}{$0.01^{*}$} \\
Gender & $\geq 60$ & 64.6 & 58.5 & \\
& Female & 77.8 & 75.0 & \multirow{2}{*}{0.68} \\
Pathologic T & Male & 72.9 & 65.8 & \\
classification & pT1 + pT2 & 78.0 & 74.3 & \\
Pathologic lymph & Negative (pN0) & 81.0 & 78.0 & \multirow{2}{*}{0.09} \\
node metastasis & Positive (pN1-pN3) & 65.7 & 58.6 & \\
TNM tumor & I + II & 81.1 & 78.3 & \multirow{2}{*}{0.21} \\
stage & III + IV & 68.3 & 60.6 & \\
Tumor & Well + Moderate & 83.3 & 80.7 & \multirow{2}{*}{ differentiation } \\
CCL18 & Poor & 55.6 & 45.5 & \\
expression & Low & 84.8 & 83.7 & \multirow{2}{*}{$0.02^{*}$} \\
\hline
\end{tabular}

Abbreviation: DFS, disease-free survival. * p-value was statistically significant using the log-rank test.

thus facilitating subsequent cancer cell metastasis [18]. Our results are in line with previous reports that show high CCL18 expression is related to lymphatic metastasis in OSCC patients.

Although lymph node metastasis often occurs during the early stage of OSCC, it is hard to detect by clinical examination or conventional imaging techniques [19]. Generally, neck dissection is the most reliable method by which to address lymph node metastasis within the neck, but this procedure can also result in a lymphatic leak, facial nerve injury, and dysfunction of the trapezius muscle. Therefore, indications for elective neck dissection in patients with clinically NO OSCC remain controversial [20]. In our study, high CCL18 expression in tumor tissue was found to be a predictor of subsequent lymph node metastasis, thus could be used as an indicator for elective neck dissection. In accordance with this, CCL18 has been suggested as a factor of predicting lymphatic metastasis in non-small cell lung cancer [21] and ovarian cancer [9].

In this study, the results of RT-qPCR demonstrated that normal oral mucosa harvested from non-malignant patients expressed CCL18 far lower than the OSCC tissue and its neighboring non-cancerous tissue. This finding is consistent with observations in a previous study on colorectal cancer patients [22]. These data suggest that CCL18 might be used as a marker for early diagnosis of OSCC.

In summary, our study suggests that CCL18 expression is a common phenomenon in OSCC tissue and expression level correlated with tumor differentiation, metastasis, and prognosis. To our knowledge, prior to this investigation, there were only in vitro and in vivo studies regarding CCL18 
and OSCC [7]. Our study provides the clinical evidence that CCL18 is closely related to the survival rate of OSCC, which is in accordance with previous studies. We demonstrate that CCL18 expression is strongly and negatively related to OS and DFS of OSCC patients and could potentially be used as a novel independent prognostic predictor of OSCC.

Supplementary information is available in the online version of the paper.

Acknowledgments: This work was supported by grants from Beijing Natural Science Foundation (7152067 to X.W), High-level Talents of Beijing Health System (2015-3-093 to X.W) and National Natural Science Foundation of China (81570991 to L.Q).We would like to thank Editage (www.editage.cn) for English language editing.

\section{References}

[1] CHOI S, MYERS JN. Molecular pathogenesis of oral squamous cell carcinoma: implications for therapy. J Dent Res 2008; 87: 14-32. https://doi.org/10.1177/154405910808700104

[2] TORRE LA, SIEGEL RL, WARD EM, JEMAL A. Global cancer incidence and mortality rates and trends--an update. Cancer Epidemiol Biomarkers Prev 2016; 25: 16-27. https:// doi.org/10.1158/1055-9965.EPI-15-0578

[3] CRUSZ SM, BALKWILL FR. Inflammation and cancer: advances and new agents. Nat Rev Clin Oncol 2015; 12: 584596. https://doi.org/10.1038/nrclinonc.2015

[4] SCHUTYSER E, RICHMOND A, VAN DAMME J. Involvement of CC chemokine ligand 18 (CCL18) in normal and pathological processes. J Leukoc Biol 2005; 78: 14-26. https://doi.org/10.1189/jlb.1204712

[5] HANAHAN D, COUSSENS LM. Accessories to the crime: functions of cells recruited to the tumor microenvironment. Cancer Cell 2012; 21: 309-322. https://doi.org/10.1016/j. ccr.2012.02.022

[6] SCHRAUFSTATTER IU, ZHAO M, KHALDOYANIDI SK, DISCIPIO RG. The chemokine CCL18 causes maturation of cultured monocytes to macrophages in the M2 spectrum. Immunology 2012; 135: 287-298. https://doi.org/10.1111/ j.1365-2567.2011.03541.x

[7] JIANG X, WANG J, CHEN X, HONG Y, WU T et al. Elevated autocrine chemokine ligand 18 expression promotes oral cancer cell growth and invasion via Akt activation. Oncotarget 2016; 7: 16262-16272. https://doi.org/10.18632/oncotarget.7585

[8] WANG H, LIANG X, LI M, TAO X, TAI S et al. Chemokine (CC motif) ligand 18 upregulates Slu expression to promote stem-cell like features by activating the mammalian target of rapamycin pathway in oral squamous cell carcinoma. Cancer Sci 2017; 108: 1584-1593. https://doi.org/10.1111/cas.13289

[9] YUAN L, WAN J, HUANG C, LIANG J, LIU M et al. Evaluation of serum CCL18 as a potential biomarker for ovarian cancer. Cancer Biomark 2017; 21: 97-104. https://doi. org/10.3233/CBM-170305
[10] SCHMID S, LE UT, HAAGER B, MAYER O, DIETRICH I et al. Local concentrations of CC-chemokine-ligand 18 correlate with tumor size in non-small cell lung cancer and are elevated in lymph node-positive disease. Anticancer Res 2016; 36: 4667-4671. https://doi.org/10.21873/anticanres.11018

[11] SU Y, ZHOU Y, SUN YJ, WANG YL, YIN JY et al. Macrophage-derived CCL18 promotes osteosarcoma proliferation and migration by upregulating the expression of UCA1. J Mol Med (Berl) 2019; 97: 49-61. https://doi.org/10.1007/ s00109-018-1711-0

[12] ZHOU Z, PENG Y, WU X, MENG S, YU W et al. CCL18 secreted from M2 macrophages promotes migration and invasion via the PI3K/Akt pathway in gallbladder cancer. Cell Oncol (Dordr) 2019; 42: 81-92. https://doi.org/10.1007/ s13402-018-0410-8

[13] ZHU X, YANG J, GAO Y, WU C, YI L et al. The dual effects of a novel peptibody on angiogenesis inhibition and M2 macrophage polarization on sarcoma. Cancer Lett 2018; 416: 1-10. https://doi.org/10.1016/j.canlet.2017.10.043

[14] MIYAGAKI T, SUGAYA M, SUGA H, OHMATSU H, FUJITA $\mathrm{H}$ et al. Increased CCL18 expression in patients with cutaneous T-cell lymphoma: association with disease severity and prognosis. J Eur Acad Dermatol Venereol 2013; 27: e60-67. https://doi.org/10.1111/j.1468-3083.2012.04495.x

[15] CHENIVESSE C, CHANG Y, AZZAOUI I, AIT YAHIA S, MORALES O et al. Pulmonary CCL18 recruits human regulatory T cells. J Immunol 2012; 189: 128-137. https://doi. org/10.4049/jimmunol.1003616

[16] CHENIVESSE C, TSICOPOUlOS A. CCL18 - Beyond chemotaxis. Cytokine 2018; 109: 52-56. https://doi. org/10.1016/j.cyto.2018.01.023

[17] SHI L, ZHANG B, SUN X, ZHANG X, LV S et al. CC chemokine ligand 18 (CCL18) promotes migration and invasion of lung cancer cells by binding to Nir1 through Nir1-ELMO1/ DOC180 signaling pathway. Mol Carcinog 2016; 55: 20512062. https://doi.org/10.1002/mc. 22450

[18] CHEN J, YAO Y, GONG C, YU F, SU S et al. CCL18 from tumor-associated macrophages promotes breast cancer metastasis via PITPNM3. Cancer Cell 2011; 19: 541-555. https:// doi.org/10.1016/j.ccr.2011.02.006

[19] PALASZ P, ADAMSKI L, GORSKA-CHRZASTEK M, STARZYNSKA A, STUDNIAREK M. Contemporary diagnostic imaging of oral squamous cell carcinoma - a review of literature. Pol J Radiol 2017; 82: 193-202. https://doi. org/10.12659/PJR.900892

[20] DE BREE R, TAKES RP, SHAH JP, HAMOIR M, KOWALSKI LP et al. Elective neck dissection in oral squamous cell carcinoma: Past, present and future. Oral Oncol 2019; 90: 87-93. https://doi.org/10.1016/j.oraloncology.2019.01.016

[21] SCHMID S, CSANADI A, KOZHUHAROV N, TCHUDJIN M, KAYSER C et al. CC-chemokine ligand 18 is an independent prognostic marker in lymph node-positive nonsmall cell lung cancer. Anticancer Res 2018; 38: 3913-3918. https://doi.org/10.21873/anticanres.12676

[22] YUAN R, CHEN Y, HE X, WU X, KE J et al. CCL18 as an independent favorable prognostic biomarker in patients with colorectal cancer. J Surg Res 2013; 183: 163-169. https://doi. org/10.1016/j.jss.2013.01.017 


\section{CCL18 overexpression predicts a worse prognosis in oral squamous cell carcinoma (OSCC)}

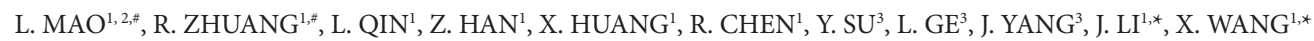

\section{Supplementary Information}

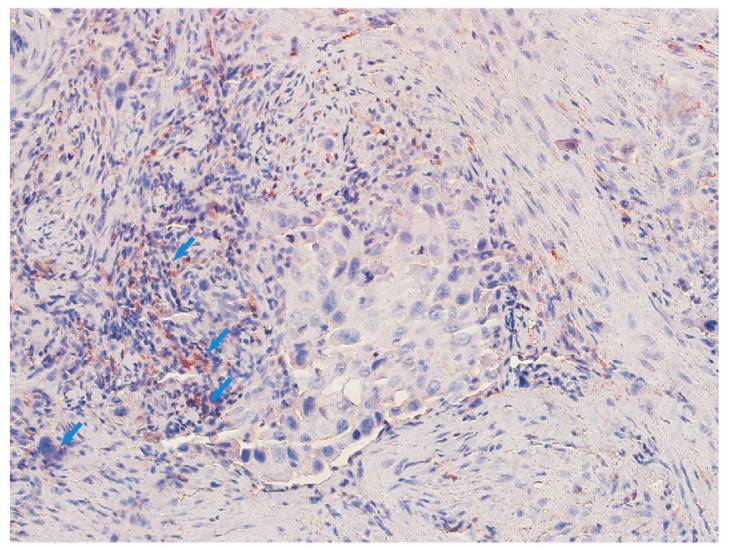

Suppl. Figure S1. CD206 expression in the interstitial tissue among the invading OSCC. It showed that CD206 (red staining) was expressed by many dense cells between the invading frontline OSCC cancerous epithelial cells. These CD206 expressing cells had smaller and rounder nuclei than other cells and some had large merged nuclei, which indicated that they are macrophages (blue arrows). Magnification 200x

Table S1. Univariate and multivariate analysis of overall survival in OSCC.

\begin{tabular}{|c|c|c|c|c|c|c|c|c|c|}
\hline \multirow{2}{*}{ Variables } & & \multicolumn{2}{|c|}{ No. of patients (\%) } & \multicolumn{3}{|c|}{ Univariate Analysis } & \multicolumn{3}{|c|}{ Multivariate Analysis } \\
\hline & & Alive & Dead & HR & $95 \% \mathrm{CI}$ & p-value & HR & 95\%CI & p-value \\
\hline \multirow{2}{*}{ Age, y } & $<60$ & $45(57.7)$ & $6(25.0)$ & 1 & & $0.009^{*}$ & 1 & & $0.005^{*}$ \\
\hline & $\geq 60$ & $33(42.3)$ & $18(75.0)$ & 3.459 & $1.362-8.784$ & & 3.83 & $1.497-9.798$ & \\
\hline \multirow{2}{*}{ Gender } & Female & $37(47.4)$ & $11(45.8)$ & 1 & & 0.74 & & & \\
\hline & Male & $41(52.6)$ & $13(54.1)$ & 1.15 & $0.504-2.623$ & & & & \\
\hline \multirow{2}{*}{ Pathologic $\mathrm{T}$ classification } & $\mathrm{T} 1$ or $\mathrm{T} 2$ & $69(88.5)$ & $19(79.2)$ & 1 & & 0.164 & & & \\
\hline & $\mathrm{T} 3$ or $\mathrm{T} 4$ & $9(11.5)$ & $5(20.8)$ & 2.024 & $0.750-5.462$ & & & & \\
\hline \multirow{2}{*}{$\begin{array}{l}\text { Pathologic lymph node } \\
\text { metastasis }\end{array}$} & Negative (pN0) & $54(69.2)$ & $11(45.8)$ & 1 & & 0.092 & & & \\
\hline & Positive (pN1-pN3) & $24(30.8)$ & $13(54.1)$ & 2.023 & $0.892-4.588$ & & & & \\
\hline \multirow{2}{*}{ TNM tumor stage } & I or II & $47(60.3)$ & $10(41.7)$ & 1 & & 0.197 & & & \\
\hline & III or IV & $31(39.7)$ & $14(58.3)$ & 1.721 & $0.754-3.929$ & & & & \\
\hline \multirow{2}{*}{ Tumor differentiation } & Well or Moderate & $60(76.9)$ & $12(50.0)$ & 1 & & $0.012^{*}$ & 1 & & $0.035^{\star}$ \\
\hline & Poor & $18(23.1)$ & $12(50.0)$ & 2.859 & $1.261-6.483$ & & 2.433 & $1.065-5.557$ & \\
\hline \multirow{2}{*}{ CCL18 expression } & Low & $44(55.7)$ & $8(33.3)$ & 1 & & $0.04^{*}$ & 1 & & $0.035^{\star}$ \\
\hline & High & $35(44.3)$ & $16(66.7)$ & 2.538 & $1.043-6.175$ & & 2.641 & $1.072-6.507$ & \\
\hline
\end{tabular}

Abbreviations: 95\% CI, 95\% confidence interval; HR, hazards ratio; OSCC, oral squamous cell carcinoma. ${ }^{*}$-value was statistically significant using the Cox proportional hazards regression model. 
Table S2. Univariate and multivariate analysis of disease-free survival in OSCC

\begin{tabular}{|c|c|c|c|c|c|c|c|c|}
\hline \multirow{2}{*}{ Variables } & & \multicolumn{2}{|c|}{ No. of Patients (\%) } & \multicolumn{3}{|c|}{ Univariate Analysis } & \multicolumn{2}{|c|}{ Multivariate Analysis } \\
\hline & & Disease-free & Disease & HR & $95 \% \mathrm{CI}$ & p-value & HR & 95\%CI \\
\hline \multirow{2}{*}{ Age, y } & $<60$ & $36(58.1)$ & $15(37.5)$ & 1 & & $0.011^{*}$ & 1 & \\
\hline & $\geq 60$ & $26(41.9)$ & $25(62.5)$ & 3.36 & $1.324-8.527$ & & 3.831 & $1.497-9.806$ \\
\hline \multirow{2}{*}{ Gender } & Female & $32(51.6)$ & $16(40.0)$ & 1 & & 0.681 & & \\
\hline & Male & $30(48.4)$ & $24(60.0)$ & 1.189 & $0.521-2.712$ & & & \\
\hline \multirow{2}{*}{ Pathologic T classification } & $\mathrm{T} 1$ orT 2 & 57 (91.9) & $31(77.5)$ & 1 & & 0.258 & & \\
\hline & $\mathrm{T} 3$ orT 4 & $5(8.1)$ & $9(22.5)$ & 1.772 & $0.658-4.776$ & & & \\
\hline \multirow{2}{*}{$\begin{array}{l}\text { Pathologic lymph node } \\
\text { metastasis }\end{array}$} & Negative (pN0) & $40(64.5)$ & $25(62.5)$ & 1 & & 0.105 & & \\
\hline & Positive (pN1-pN3) & $22(35.5)$ & $15(37.5)$ & 1.969 & $0.869-4.462$ & & & \\
\hline \multirow{2}{*}{ TNM tumor stage } & I or II & $37(59.7)$ & $20(50.0)$ & 1 & & 0.224 & 1 & \\
\hline & III or IV & $25(40.3)$ & $20(50.0)$ & 1.669 & $0.731-3.806$ & & & \\
\hline \multirow{2}{*}{ Tumor differentiation } & Well or Moderate & $50(80.6)$ & $22(55.0)$ & 1 & & $0.006^{*}$ & 1 & \\
\hline & Poor & $12(19.4)$ & $18(45.0)$ & 3.14 & $1.382-7.136$ & & 2.809 & $1.232-6.403$ \\
\hline \multirow{2}{*}{ CCL18 expression } & Low & 37 (59.7) & $14(35.0)$ & 1 & & $0.032^{*}$ & 1 & \\
\hline & High & $25(40.3)$ & $26(65.0)$ & 2.642 & $1.086-6.426$ & & 2.961 & $1.205-7.279$ \\
\hline
\end{tabular}

Abbreviations: 95\% CI, 95\% confidence interval; HR, hazards ratio; OSCC, oral squamous cell carcinoma. ${ }^{*}$ p-value was statistically significant using the Cox proportional hazards regression model. 